\title{
A Case Report of Pediatric Epstein Barr Virus (EBV) Related Cholestasis from Al-Adan Hospital, Kuwait
}

\author{
Fawaz Al-Refaee*, Sarah Al-Enezi, Enamul Hoque, Assad Albadrawi \\ Department of Pediatrics, Al-Adan Hospital, Ministry of Health, Kuwait, Kuwait \\ Email: dralrefaee@gmail.com
}

Received 7 January 2015; accepted 5 February 2015; published 9 February 2015

Copyright ( 2015 by authors and Scientific Research Publishing Inc.

This work is licensed under the Creative Commons Attribution International License (CC BY).

http://creativecommons.org/licenses/by/4.0/

(c) (i) Open Access

\begin{abstract}
Infectious mononucleosis is an acute illness due to Epstein Barr virus infection, which occurs commonly in young adults. Liver involvement in acute EBV infection occurs in up to $95 \%$ of patients between the 6th and 15th day of illness and is usually mild [1]. Here we report on a 7-year-old girl treated by Gastroenterology, Hepatology, and Nutrition Unit of Al-Adan Hospital pediatric Department, presented with prolonged fever, lymphadenopathy, generalized edema, hyperbilurubinemia and elevated liver enzymes secondary to EBV infection. This case represents a rare presentation of common viral infection in pediatric population.
\end{abstract}

\section{Keywords}

Epstein Barr Virus (EBV)

\section{Introduction}

Epstein-Barr virus (EBV) infection typically causes the clinical syndrome of infectious mononucleosis. Liver involvement is usually mild, and resolves spontaneously [2]. Hepatitis with mild transient elevations in serum aminotransferases is often reported in Epstein-Barr virus (EBV) infectious mononucleosis. Mild jaundice develops in approximately $5 \%$ of cases and may result from cholestasis or virus-induced hemolysis [3]. However, the majority of patients recover without apparent sequelae and most patients will need only supportive treatment.

\section{Case Report}

A 7-year-old girl previously well was admitted to our hospital with a history of fever for 10 days, decreased ap"Corresponding author.

How to cite this paper: Al-Refaee, F., Al-Enezi, S., Hoque, E. and Albadrawi, A. (2015) A Case Report of Pediatric Epstein Barr Virus (EBV) Related Cholestasis from Al-Adan Hospital, Kuwait. Open Journal of Pediatrics, 5, 23-26. 
petite, malaise and abdominal pain. No history of vomiting or diarrhea, no skin rash, and no headache. In the first 5 days of her illness prior of admission, she was evaluated by a family physician and found to have pharyngitis and she was treated with oral Amoxicillin Clavulanate 45 mg/kg/day every 12 hours for 7 days.

On admission she was looking well but irritable, hydrated, febrile T: 40c, HR: 140/min RR: 30/min, BP: 101/65 mmgh, Capillary refilling time was 2 seconds. She had bilateral palpable cervical lymph nodes 5 mm size each. Abdominal examination revealed tenderness all over the abdomen with no signs of peritonitis, liver was enlarged $3 \mathrm{~cm}$ below costal margin and spleen was not palpable. The rest of the clinical examination was unremarkable.

Initial blood investigation showed, CBC white count of $9 \times 10^{9} / \mathrm{L}, \mathrm{Hb}: 109 \mathrm{~g} / \mathrm{L}$, platelet 126 . Liver function test (LFT) showed: LDH 587 U/L, ALT 126 U/L, ALP 315 U/L, AST 124 U/L, total bilirubin 18.10 micromol/L, direct bilirubin 12.5 micromol/L. Renal function and serum electrolyte were normal, CRP: 60, ESR: $11 \mathrm{~mm} / \mathrm{hr}$, paracetamol level was within normal range. Coagulation profile showed INR: 1.3 seconds.

Widal test normal and Brucella antibody was negative. Urine and blood culture were negative. Blood virology (EBV, CMV, Hepatitis A, B and C) were taken. Ultrasound of the abdomen done at Emergency Room with no evidence of gallstones or ascites or other abnormal findings.

Patient was treated as a case of pyrexia from unknown origin (PUO) and covered with Intravenous broad spectrum antibiotics, but with no improvement in her symptoms. Few days later, she had ever abdominal pain with fever, so U/S abdomen was repeated and revealed hepatosplenomegaly, contracted gallbladder with thick edematous wall, mild free fluid in the abdomen and the right iliac fossa. Computed Tomography (CT) abdomen with contrast was done which showed minimal fluid in the pelvis with no other abnormalities, so surgical causes needed to be rolled out at this point.

Furthermore, a diagnostic laparoscopy was normal, with unremarkable peritoneal fluid analysis and culture. She became clinically jaundiced and developed generalized edema. Her clinical examination at that time revealed irritable, febrile, pale and icteric young girl, but no signs of chronic liver disease were elicited. She had remarkable edema of face, abdomen and extremities. Her vital signs showed, RR: 30/min, P: 125/min, oxygen saturation was: 98\% in room air and BP 100/60 mmhg. Abdomen was distended with generalized tenderness, moderate enlargement of the liver and spleen noted and evidence of shifting dullness were present. Other systemic examination was unremarkable.

Blood investigation was repeated, complete blood count revealed elevated white count with lymphocyte predominance and borderline platelet count at $154 \times 10^{9}$. Peripheral blood film showed reactive lymphocytosis. A repeat of her liver profile showed total: Bilirubin: 103 micromol/L with predominant direct fraction of 89.3 micomol/l. Her liver enzymes showed mainly a cholestatic pattern with significant elevation of GGT and ALP 427 $\mathrm{U} / \mathrm{L}$ and $867 \mathrm{U} / \mathrm{L}$ respectively.

Albumin was low at $24 \mathrm{~g} / \mathrm{l}$. Her serum glucose, renal function test and electrolytes were normal. A repeat of coagulation profile: showed significant coagulopathy consistent with acute liver failure of INR 2.2.

Blood virology previously done confirmed acute EBV infection (PCR + IgM).

She was treated conservatively with Albumin infusions, Ursodeoxycholic acid, fresh frozen plasma and intravenous Vitamin K.

The patient continued to have high grade fevers along with the presence of generalized lymphadenopathy, bone marrow examination was done showed marginally increased relative proportion of lymphocytes with presence of 8 - 10 atypical (reactive) lymphocytes, no evidence of blast cells and no evidence of hematological malignancy was present.

Finally, after two weeks of admission, she had gradual clinical improvement. Liver enzymes and total bililrubin were dropping and she was discharged in stable condition. The patient underwent a repeat of liver function tests and ultrasound abdomen two weeks after discharge both of which were normal (Table 1).

\section{Discussion}

EBV is a ubiquitous human herpesvirus that is usually transmitted through close personal contact among young children and via intimate oral contact among adolescent and young adults [4]. Contact of Epstein-Barr virus (EBV) with oropharyngeal epithelial cells allows replication of the virus, release of EBV into the oropharyngeal secretions, and infection of B cells in the lymphoid-rich areas of the oropharynx [5].

The incubation period prior to the development of symptoms averages four to eight weeks [6]. The cardinal 
Table 1. The patient’s laboratory parameters overtime.

\begin{tabular}{|c|c|c|c|c|}
\hline Parameters & At admission & At day 8 & On discharge & References range \\
\hline Hemoglobin & 109 & 90 & 90 & $100-140 \mathrm{~g} / \mathrm{L}$ \\
\hline Total white count & 10.67 & 22.6 & 18.6 & $5-19.5 \times 10^{9}$ \\
\hline Neutrophil & 23 & 9.4 & 8.8 & $30 \%-50 \%$ \\
\hline Lymphocyte & 61 & 86.2 & 87 & $38 \%-58 \%$ \\
\hline Total bilirubin & 18 & 132.6 & 50.5 & 0 - $17 \mathrm{Micmol} / \mathrm{L}$ \\
\hline Direct bilirubin & 12.8 & 111.9 & 39.7 & 0 - $7 \mathrm{Micmol} / \mathrm{L}$ \\
\hline ALT & 126 & 40 & 46 & $7-55 \mathrm{U} / \mathrm{L}$ \\
\hline AST & 124 & 87 & 120 & 8 - $48 \mathrm{U} / \mathrm{L}$ \\
\hline ALP & 315 & 799 & 759 & $45-115 \mathrm{U} / \mathrm{L}$ \\
\hline GGT & - & 400 & 601 & $9-48 \mathrm{U} / \mathrm{L}$ \\
\hline PT & 14.8 & 24.5 & 13.3 & 9.5 - 13.8 seconds \\
\hline INR & 1.3 & 2.2 & 1.2 & $0.8-1.2$ \\
\hline Albumin & 31 & 24 & 38 & $35-55 \mathrm{~g} / \mathrm{dL}$ \\
\hline
\end{tabular}

Abbreviations: ALT: alanine transaminase; AST: aspartate aminotransferase; ALP: alkalinephosphatase; GGT: $\gamma$ glutamyltransferase; PT: prothrombin time; INR: international normalized ratio; U/L: units per liter.

symptoms of infectious mononucleosis are the well-known triad of fever, pharyngitis, and peripheral lymphadenopathy, especially involving the posterior cervical chains. A minority of patients have splenomegaly, gastrointestinal symptoms, rash, and headache [7].

Our patient had initially the clinical presentation of infectious mononucleosis but the prolonged fever and cholestatis made us think about other differential diagnosis like autoimmune hepatitis, alpha-1 antitrypsin deficiency and other. Recently EBV-induced hepatitis has been recognized as an important cause of cholestasis [8]. Sever cholestasis is rare and the mechanism is unknown. High concentrations of enzyme-inhibiting autoantibodies against the antioxidative enzyme, manganese-superoxide dismutase (MSD), have been postulated to play a role [9], but support for this concept is limited. In adults, Hepatitis caused by EBV is common, mild, and self limiting, although fulminant hepatic failure has been reported in 17 patients worldwide, with an overall mortality of $85 \%$ [10].

During the acute stage of her illness, our patient had serial abdominal sonography which was done because of the persistant abdominal pain throughout hospital admission. However, all of them had shown edematous gallbladder with thickened wall. Gallbladder wall thickening is rare in infectious mononucleosis syndromes and has been proposed as a sign of severity of the infectious mononucleosis and as an indicator for the need to carefully monitor the clinical course [11].

EBV has been associated with a variety of malignancies, particularly lymphoma. Many of these infections are subclinical, but Hodgkin lymphoma has been associated with a history of infectious mononucleosis [6], based on that, this girl had bone marrow examination to rule out possible hidden malignancies. Although of all of these complications and liver involvement, this girl responded well to the supportive treatment.

\section{Conclusion}

Atypical presentations of Epstein-Barr virus (EBV) infection are more common with increasing age but can also 
be seen in young children. All pediatricians should be aware of various presentations of common viral childhood infection in order to provide a comprehensive cascade of investigation and supportive management for those children. The good news is that most of the viral infections are self limited and rarely can lead to significant morbidity and mortality in immunocompotent patients.

\section{References}

[1] Rapp Jr., C.E. and Hewetson, J.F. (1978) Infectious Mononucleosis and the Epstein-Barr Virus. American Journal of Diseases of Children, 132, 78-86.

[2] Barlow, G., Kilding, R. and Green, S. (2000) Epstein-Barr Virus Mimicking Extra-Hepatic Biliary Obstruction. Journal of the Royal Society of Medicine, 93, 316-318.

[3] Jenson, H.B. (2000) Acute Complications of Epstein-Barr Virus Infectious Mononucleosis. Current Opinion in Pediatrics, 12, 263-268. http://dx.doi.org/10.1097/00008480-200006000-00016

[4] Hoagland, R.J. (1955) The Transmission of Infectious Mononucleosis. The American Journal of the Medical Sciences, 3, 229-262.

[5] Anagnostopoulos, I., Hummel, M., Kreschel, C. and Stein, H. (1995) Morphology, Immunophenotype, and Distribution of Latently and/or Productively Epstein-Barr Virus-Infected Cells in Acute Infectious Mononucleosis: Implications for the Interindividual Infection Route of Epstein-Barr Virus. Blood, 85, 744-750.

[6] Aronson, M.D. and Auwaerter, P.G., Hirsch, M.S., Kaplan, S.L. and Mitty, J., Eds. Infectious Mononucleosis in Adults and Adolescents. UpToDate.

[7] (1972) General Features of Infectious Mononucleosis (Roundtable Discussion). In: Glade, P.R., Ed., Infectious Mononucleosis: Proceedings of Symposium, New York, 7 April 1972, Philadelphia, JB Lippincott, 1-18.

[8] Shaukat, A., Tsai, H.T., Rutherford, R. and Anania, F.A. (2005) Epstein-Barr Virus Induced Hepatitis: An Important Cause of Cholestasis. Hepatology Research, 33, 24-26. http://dx.doi.org/10.1016/j.hepres.2005.06.005

[9] Juttner, H.U., Ralls, P.W., Quinn, M.F., et al. (1982) Thickening of the Gall-Bladder Wall in Acute Hepatitis: Ultrasound Demonstration. Radiology, 142, 465-466. http://dx.doi.org/10.1148/radiology.142.2.7054838

[10] Patel, S., Zuckerman, M. and Smith, M. (2003) Real-Time Quantitative PCR of Epstein-Barr Virus BZLF1 DNA Using the LightCycler. Journal of Virological Methods, 109, 227-233. http://dx.doi.org/10.1016/S0166-0934(03)00076-4

[11] Yamada, K. and Yamada, H. (2001) Gallbladder Wall Thickening in Mononucleosis Syndromes. Journal of Clinical Ultrasound, 29, 322-325. http://dx.doi.org/10.1002/jcu.1042 
Scientific Research Publishing (SCIRP) is one of the largest Open Access journal publishers. It is currently publishing more than 200 open access, online, peer-reviewed journals covering a wide range of academic disciplines. SCIRP serves the worldwide academic communities and contributes to the progress and application of science with its publication.

Other selected journals from SCIRP are listed as below. Submit your manuscript to us via either submit@scirp.org or Online Submission Portal.
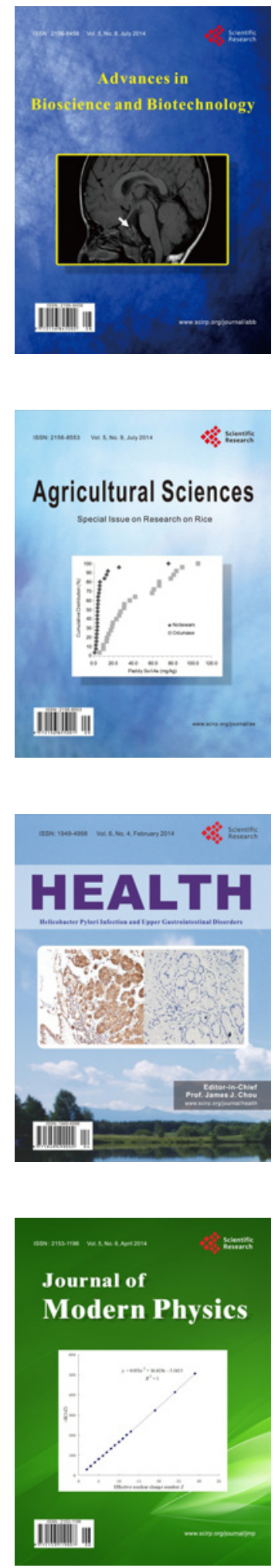
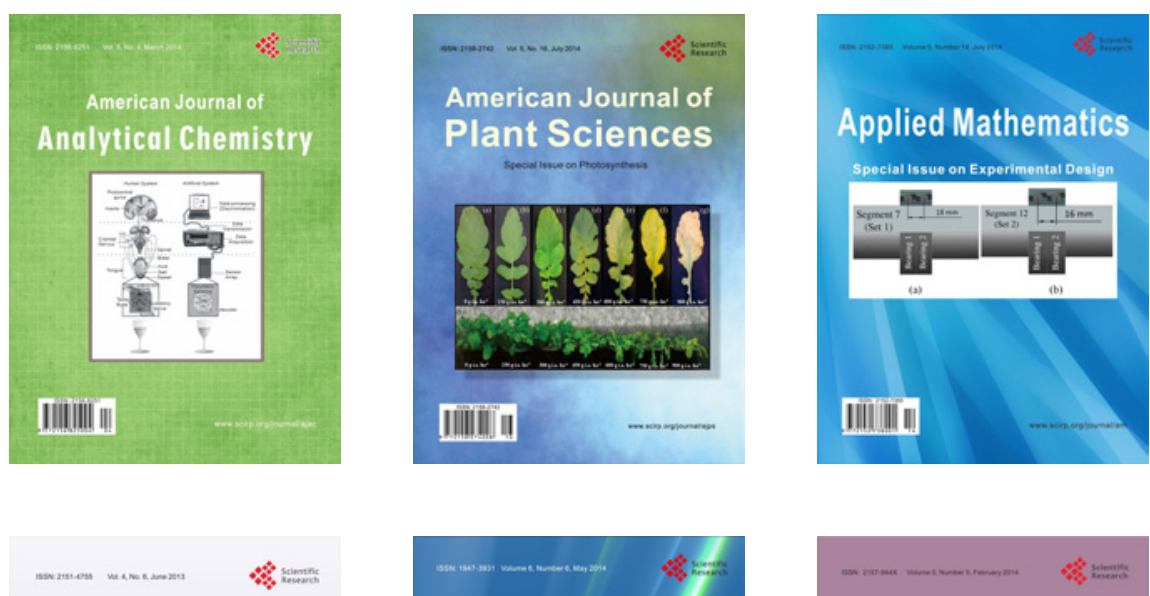

Creative Education
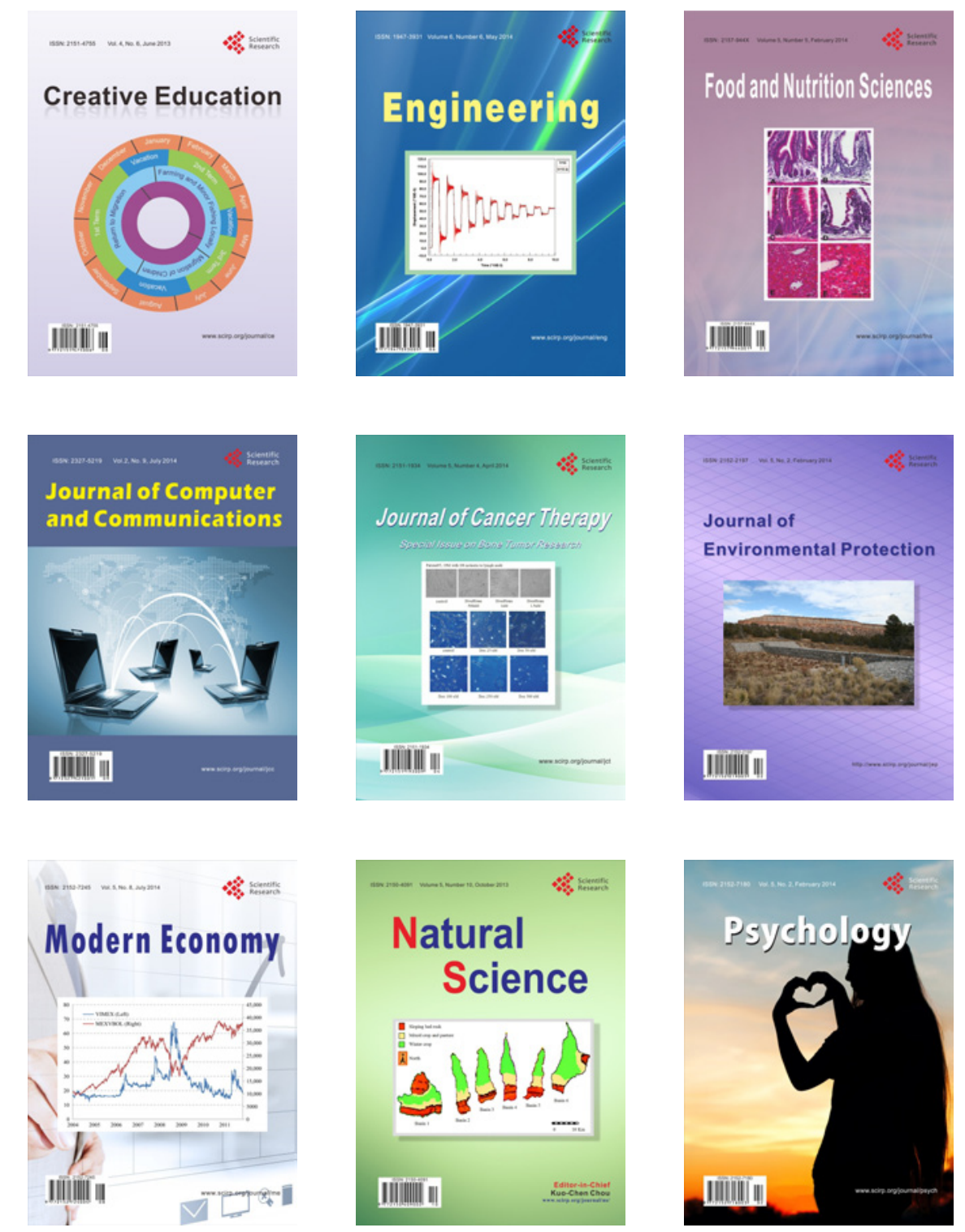